\title{
СТРАТЕГИИ ТРУДОУСТРОЙСТВА УЧИТЕЛЕЙ В МЕГАПОЛИСЕ И ДИФФЕРЕНЦИАЦИЯ ШКОЛ
}

\begin{abstract}
Школы в больших городах дифференцируются по уровню престижа, качества образования и квалификации учителей. В статье анализируется один из механизмов, который приводит к неравномерному распределению квалифицированных учителей по школам - стратегии педагогов при выборе места работы. Мы предполагаем, что стратегии поиска работы в значительной степени зависят от квалификации и профессиональных достижений учителя. Это исследование выполнено на материале интервью с учителями $(\mathrm{N}=49)$, работающими в школах различного статуса (общеобразовательных, с углубленным изучением какого-либо предмета, гимназиях) в двух районах Санкт-Петербурга. Мы рассматриваем выбор школы при первоначальном трудоустройстве и при смене места работы. Анализ интервью показал, что на рынке труда учителей сосуществуют разные модели трудоустройства, сближающие его и с рынком квалифицированного, и с рынком неквалифицированного труда. В рамках «аутсайдерской» стратегии школы рассматриваются как организации-потенциальные наниматели, тогда как «инсайдерская» перспектива ориентирована на коллектив, к которому учитель стремится присоединиться. В сегменте престижных школ учителя при выборе места работы обращают внимание прежде всего на условия труда, в то время как в непрестижных - на географическое расположение. Для рынка труда педагогов характерны инбридинг (наем выпускников школы на работу в ней), трудоустройство в школу, где обучаются дети, коллективный переход учителей на новое место работы. Наряду с результатами исследования обсуждаются выводы для образовательной политики в области обеспечения равных
\end{abstract}

Влада Вячеславовна Баранова - к.и.н., доцент департамента социологии, НИУ ВШЭ, Санкт-Петербург, Россия. Электронная почта: vbaranova@hse.ru

Кирилл Александрович Маслинский - научный сотрудник Лаборатории социологии образования и науки, НИУ ВШЭ, Санкт-Петербург, Россия. Электронная почта: kmaslinsky@hse.ru 
образовательных возможностей. Мы предполагаем, что паттерны поиска и смены места работы среди учителей могут быть механизмом привлечения квалифицированных учителей в менее престижные школы.

Ключевые слова: школа, учителя, профессиональная группа, стратегии трудоустройства, дифференциация школ, образовательное неравенство

DOI: 10.17323/727-0634-2017-15-2-281-296

Это исследование направлено на изучение стратегий трудоустройства учителей в большом российском городе. Проблеме привлечения в школу и удержания высококвалифицированных учителей посвящена значительная литература (Hanushek et al. 2004; Ingersoll 2001), равно как и условиям, влияющим на решение молодых учителей остаться в профессии (Маслинский, Иванюшина 2016). В исследованиях рынка труда педагогов исходят из понимания трудоустройства как двунаправленного процесса, результат которого зависит не только от возможностей доступа к кандидатам и политики найма со стороны школы, но и от механизмов поиска самого учителя (Maier, Youngs 2009; Boyd et al. 2006). Нас интересуют факторы выбора места работы и предложенная репрезентация трудоустройства, с целью понимания тех процессов, которые обуславливают неравномерное распределение квалифицированных учителей по школам.

\section{Чего учителя хотят от школы, а администрация от учителя?}

Рынок труда учителей в высокой степени сегментирован и локализован в пространстве: ни наниматели, ни соискатели здесь не выбирают из всех возможных вариантов в масштабе страны или даже региона. Например, в США учителя стараются найти школу недалеко от дома или в районе, похожем на тот, в котором они родились и выросли (Boyd et al. 2005). Boзможности школы по привлечению квалифицированных учителей, таким образом, во многом определяются ее географическим положением, заработной платой и условиями труда, однако не менее важную роль играет состав учащихся. Предпочтение отдается школам с менее проблемным «контингентом» учащихся (Lankford et al. 2002), а опытные учителя при переходе в другую школу в среднем не выигрывают в уровне оплаты труда, но часто оказываются в школах с более высоким социальным статусом учащихся (Hanushek et al. 2004). Подобное положение способствует усугублению образовательного неравенства, поскольку дети из низкостатусных семей имеют меньший доступ к обучению у квалифицированных учителей (Akiba et al. 2007), а в школах, которые посещают дети бедного городского населения, в среднем ниже квалификация учителей и выше текучесть персонала (Jacob 2007; Ingersoll 2001). 
Насколько подобные проблемы актуальны для России? Школы часто оказываются в неравном положении в отношении найма квалифицированных учителей, особенно в сельской местности (Константиновский 2008), однако и в больших столичных городах средний уровень образования и квалификации учителей в разных школах варьируется: в элитных школах процент педагогов высшей категории несколько выше, чем в обычных школах - 45,6\% и 40,4\% соответственно (Косарецкий и др. 2015: 40). Квалификация учителей выступает одним из независимых факторов, влияющих на образовательные результаты школы, в частности, успешность сдачи ЕГЭ зависит среди прочего и от качества педагогического состава (Дербишир, Пинская 2016: 115). Тем не менее зависимость между составом педагогов и формальным типом школы или ее успешностью в отношении образовательных результатов (ЕГЭ) не является критической, хотя в гимназиях, лицеях, школах с устойчиво высокими результатами ЕГЭ уровень образования учителей и их квалификационные категории в среднем выше, чем в общеобразовательных школах и школах с устойчиво низкими результатами ЕГЭ (Вахштайн и др. 2009; Пинская и др. 2012).

Опрос педагогов в рамках нашего проекта по изучению учителей в Санкт-Петербурге не выявил значимых различий между общеобразовательными школами и гимназиями, лицеями и школами с углубленным изучением какого-либо предмета ни по социально-демографическим характеристикам учителей (гендер, возраст, тип и уровень образования, миграционный статус), ни по таким установкам как отношение к ученикам, самоэффективность (self-efficacy), лояльность к профессии и к конкретной школе (Иванюшина, Александров 2016).

Эти данные позволяют говорить о том, что образовательное неравенство (измеряемое в успешности учеников при сдаче ЕГЭ) в российском контексте связано в большей степени с социальным составом учеников и их семей, а не с составом педагогических кадров. Руководители успешных школ стремятся привлечь детей из семей с высоким социоэкономическим статусом (Дербишир, Пинская 2016). Значит ли это, что в отношении доступа к квалифицированным педагогам, неравенство увеличивается не так существенно как, например, в отношении доступа к репетиторам или дополнительному образованию? Мы предполагаем, что ответ на эти вопросы отчасти могут дать сведения о формировании школьных коллективов и стратегиях трудоустройства учителей.

Как выглядит рынок труда учителей и связаны ли стратегии поиска работы со статусом школы? Исследования показывают, во-первых, что учителя работают в одной и той же школе в среднем более 15 лет (Ленская 2015: 7). Таким образом, от того, как учителя выбирают первую школу в карьере и при каких условиях они меняют место работы, во многом зависит распределение учителей по школам на длительный срок. По данным мониторинга экономики образования, при выборе места работы учителя 
«больше всего обращают внимание на хорошие отношения в коллективе и с руководством, а также на приемлемые условия труда (близость работы к дому, гибкий график и т.п.)» (Рощина, Филиппова 2012:31). Эти представления, по-видимому, корректируются под влиянием географических факторов, а также возможной конкуренцией, связанной с оплатой труда в школах с более высокими академическими результатами она в среднем выше (Дербишир, Пинская 2016: 118).

В статье школьные коллективы рассматриваются не с точки зрения социально-демографических характеристик учителей, а с точки зрения мотивов и стратегий устройства на работу в конкретную школу. Как складывается школьный коллектив? Насколько случайным или неслучайным оказывается трудоустройство в определенную школу и как индивид интерпретирует те или иные события в своей профессиональной биографии?

\section{Данные и метод}

Данные собраны в рамках проекта по изучению социального профиля учителей в Санкт-Петербурге. Анализ количественных данных отражен в ряде публикаций (Иванюшина, Александров 2016; Маслинский, Иванюшина 2016), однако в этой статье мы сосредоточились на анализе интервью с учителями. Полуструктурированные интервью о профессиональной биографии проводились в школе, обычно во время «окна» учителя, т.е. зачастую продолжались один урок (примерно 45 минут). Гайд включал вопросы об образовании и карьере, профессиональной идентичности, особое внимание уделялось моментам выбора профессии, трудоустройства в первую школу и обстоятельствам, сопровождавшим смену места работы, удовлетворенности работой и возможным планам по смене места работы.

Всего записано 49 интервью с учителями с различным стажем работы, представляющими основные школьные дисциплины $(\mathrm{N}=38)$ и учителями начальных классов (11 из 49) в 18 школах, относящихся к Василеостровскому (11 школ) и Невскому (6) районам, и в одной математической гимназии для старших классов общегородского набора. Для проведения исследования отбирались школы разного типа (средние общеобразовательные - 8; с углубленным изучением какого-либо предмета - 5; лицеи, гимназии - 5) и с разным уровнем академических успехов учеников (оцениваемых по средним результатам ЕГЭ на фоне школ района). В качестве дополнительного материала мы опираемся на интервью с директорами школ, в которых обсуждались в том числе стратегии найма учителей и отдельные случаи успешного или неуспешного трудоустройства (дополнительные 10 интервью).

При анализе интервью мы рассматривали, как респонденты конструируют свою профессиональную биографию и объясняют решения о поступлении на работу в конкретную школу. Были выделены истории начала работы в школе по аналогии с предложенной для анализа нарративов 
учителей категорией "elevator stories" - коротких и социально приемлемых историй трудоустройства в школах, которые позволяют индивиду объяснить выбор и смену места работы (Schaefer et al. 2014:2; см. также Lindqvist, Nordänger 2016). Мы рассматриваем два типа ситуаций трудоустройства: первое место работы учителем (выбор школы) и переход в другую школу. Среди наших респондентов довольно много учителей, приехавших из других регионов, но поскольку в фокусе исследования находится локальный рынок труда учителей, для них первое трудоустройство в школу в Петербурге мы считаем точкой входа, поэтому рассматриваем эти ситуации в одном ряду с выбором первого места работы. Эти истории и предложенные мотивировки после обсуждения получали условные ярлыки («безальтернативный выбор», «поиск вакансий», «поиск знакомств») и затем каждая группа интерпретировалась в контексте сведений об образовании и карьере учителя и статусе школы.

\section{Выбор школы}

Прежде чем анализировать стратегии трудоустройства, рассмотрим критерии, которые учителя предлагали в интервью в качестве объяснительной модели работы в своей школе по сравнению с другими школами. Хотя не все педагоги обозначали устройство на работу термином «выбор», в историях трудоустройства озвучивались критерии, которые считались важными для будущего места работы или те параметры, которые им важны сейчас. Риторически это часто оформляется как противопоставление «в других местах может быть то-то и то-то, но здесь...».

\section{“Недостатки элитных школ»}

Учителя общеобразовательных школ склонны рационализировать свое положение в непрестижном школьном сегменте, подчеркивая отрицательные качества работы в престижных школах, связанные с высокой конкуренцией среди потенциальных учителей и относительно высоким социальным положением родителей. Учитель информатики в одной из общеобразовательных школ после окончания педагогического вуза не стремился устроиться в известные математические школы города, так как там «без степени [кандидата наук] так и будешь пятые классы вести», а в обычной школе он уже в молодом возрасте смог занять административную должность (заместитель директора) и преподавать в старших классах (СОШ, ${ }^{1}$ м., информатика). Учительница химии в общеобразовательной школе, приехавшая из другого города, упоминает, что отказывалась

\footnotetext{
Здесь и далее будут использоваться сокращенные обозначения типов школ: СОШ - средняя общеобразовательная школа, СШ <предмет> - средняя школа с углубленным изучением указанного предмета.
} 
от предложений устроиться в районный лицей, указывая на напряженную атмосферу, характеризующуюся высоким уровнем претензий родителей к учителям (СОШ, ж., химия).

\section{Географическая близость}

Как уже упоминалось, географический фактор чрезвычайно значим в распределении учителей по школам, однако чаще он упоминался в качестве критерия по умолчанию: «обзванивал школь в округе, в этой первой взяли трубку, в других никто не подходил к телефону» (СОШ, м., учитель физкультуры). Устройство на работу произошло, таким образом, под влиянием отбора со стороны школы (ответили на телефонный звонок), однако выбранные номера были предопределены округом. В таком случае школа рассматривается как безотказный трудовой ресурс, в котором всегда найдется работа, даже если она не объективирована в форме опубликованных вакансий. За этой моделью стоит представление о том, что школы одинаковы, и это, на наш взгляд, сближает механизмы трудоустройства в этой группе учителей с трудоустройством в массовых профессиях, не требующих квалификации (кассир, уборщик и т.п.), где принцип географической близости играет для соискателя решающую роль. При более высоких требованиях учителя близость к дому не упоминается в качестве важного параметра или оказывается на второстепенной позиции в ряду других критериев.

\section{Стратегии трудоустройства}

В историях трудоустройства прослеживаются две стратегии соискателей, которые можно условно обозначить как (1) поиск вакансий и (2) поиск знакомств в учительской среде. Разумеется, стратегии могут комбинироваться, однако в нарративах учителей одна из них занимает центральное место.

\section{Вакансии}

Стратегию поиска доступных вакансий можно иначе и более обобщенно обозначить как подход к трудоустройству, при котором будущий учитель занимает «аутсайдерскую» позицию по отношению к школе. Школа с этой точки зрения предстает прежде всего как организация-работодатель, а в ситуации выбора актуализируются различные свойства (престиж, уровень оплаты, географическое положение), делающие ее более или менее привлекательной для соискателя. В интервью описываются несколько процедур поиска работы, в которых реализуется эта стратегия.

Первая процедура - собственно поиск и сравнение вакансий через интернет. В этом сценарии учителя озвучивают как собственно профессиональные запросы к потенциальному месту работы, так и другие прагматические соображения и описывают процесс выбора школы в общерыночных терминах уровня оплаты и условий труда. Например, учитель- 
ница химии перед переездом в Петербург вслед за мужем выбрала школу с химико-биологическим уклоном (по количеству часов и потому, что «понимала, что в химической школе я смогу химией заниматься так... углубленно, что мне в общем-то нравится»), созвонилась и поступила на работу после собеседования. В прошлой школе, где она работала, были профильные химико-биологические классы, «и по этой причине меня взяли сюда, потому что просто учителя из обычной школь не взяли бы» (СШ химия, ж., химия).

Подобная стратегия не требует социальных связей внутри школьного сообщества: учитель воспринимает себя как профессионала, обладающего определенной квалификацией и конкурентоспособностью на рынке:

Я мониторила вакансии с разной работой, увидела эту, отправила резюме, мне поступил звонок, я пришла на собеседование, мне рассказали, что и как, какая нагрузка, приблизительная оплата труда, что преподаватель нужен срочно, это не временная вакансия. Плюс школа находится рядом с домом, я не трачу много времени, живу на Сенной площади (СШ гуманитарные предметы, ж., учитель английского языка).

Выбор сегмента рынка, в котором рассматривают вакансии педагоги, следующие этой стратегии, явно связан с уровнем престижа их собственного образования и опыта работы и подтверждает наличие барьеров по уровню квалификации. Как правило, учителя престижных школ с высоким уровнем образования позиционируют себя как профессионала, имеющего выбор при трудоустройстве. Так, выпускница филологического факультета РГПУ им. Герцена училась в Швейцарии, а потом в СПбГУ по специальности «История искусства», и описывает, как выбирала из нескольких вариантов престижных общегородских гимназий (гимназия, учитель русского языка и литературы; МХК на французском языке).

Помимо выбора школы по профессиональным и прагматическим соображениям, в многочисленную группу выделяются те учителя, которые заявляют, что устроились «куда взяли». Предельным случаем этой же модели является обращение в РОНО, которому в данном случае делегируется выбор вакансии. Обычно в таких нарративах процедура поиска работы описывается как последовательный контакт с ближайшими школами, маркированный даже в лексическом выборе словами «обходить», «обзванивать»:

Я говорю, у меня очень специфическая судьба жены военного. Тогда была другая эпоха, Советский Союз, другие задачи. В школу - значит в школу. <... Приехала с Дальнего Востока, прошла по нескольку школ, где было место - туда я и определилась (СШ английский язык, ж., учитель истории).

Стратегия поиска работы через знакомства в учительской среде («инсайдерская») предполагает, что школа выступает прежде всего как социальная группа, в которую стремится войти будущий учитель. Актуализируются социальные связи со школьными учителями и администрацией, ситуации 
контакта с коллективом, разделяемые ценности и идентичности. Помимо отдельных упоминаний рекомендаций знакомых и родственников, характерных и для других сегментов рынка труда, выделяются несколько видов социальных контактов, специфических для трудоустройства школьных учителей, к рассмотрению которых мы и обратимся далее.

\section{Инбридинг}

Одним из самых перспективных для будущего трудоустройства в школу механизмов создания связей в коллективе учителей оказывается обучение в школе. Инбридинг чрезвычайно распространен в школах вне зависимости от типа, впрочем, конкретные механизмы различаются в разных типах школ. В престижных физико-математических школах с советского времени существует модель раннего вовлечения выпускников и студентов университета в преподавание через стажеров в кружках для одаренных детей или через вожатых и преподавателей в летних образовательных лагерях. Для понимания этого механизма подробнее рассмотрен кейс одной из математических школ для старшеклассников общегородского набора (шесть интервью с учителями алгебры, геометрии или информатики от 24 до 40 лет). Все они участвовали в той или иной форме вовлечения в преподавание во время обучения в университете или даже в старших классах:

Я с 5 класса ходил на кружки, а потом учился в организации, в которой сейчас вот работаю. То есть у меня это непрерывный процесс лет с 10. Вот потом в 16 лет, когда я учился в 11 классе, я стал стажером помогать на кружках. Вот. А потом в тот момент так сложилось, что у меня уже было высшее образование, я думал, почему бы мне не поработать... ну, это естественный процесс (лицей, м., алгебра и геометрия).

Примечательна рефлексия одного из респондентов, не учившегося в физико-математической школе: «в отличии от меня, они [коллеги], видимо, выпускники такой же системы, не обязательно [название школы], какой-то или каких-то различных систем в Питере» (лицей, м., информатика). Это наблюдение подтверждается интервью - учителя упоминали, что заканчивали эту или другие известные математические школы.

Однако распространена стратегия инбридинга и в обычных школах, куда выпускники приходят преподавать после педагогических вузов, мотивируя это решение тем, что они знают учителей и учителя знают их. Движущими силами инбридинга здесь выступают личный пример учителя и личные отношения с ним. Знакомства в «родной школе» могут быть использованы как ресурс и в нестандартных профессиональных траекториях. Например, одна из наших респонденток пришла работать в школу из НИИ в начале 1990-х гг. с предложением преподавать экономику в той школе, которую сама заканчивала и где для нее открыли новый предмет (СШ английский язык, ж., учитель экономики). Инбридинг может объединяться в школе и с внутрисемейным воспроизводством профессии: учительница 
географии еще во время обучения начала работать в школе, где работала ее мать (тоже преподавательница географии).

Неожиданно распространенным путем приобретения знакомств в школьном коллективе, приводящем затем к трудоустройству, оказались контакты с учителями в школах, где учатся дети респондентов. Этот не слишком значительный социальный ресурс, тем не менее позволяет «зацепиться» в школе. Такой сценарий более характерен для тех, кто не работал учителем ранее:

Хотя я тут оказалась волею случая, но, задержавшись возле своего ребенка, я как-то... Мы семья военнослужащих, сюда направили, дочь ходила в эту школу, жили в общежитии и искала работу... Сначала на продленную группу пришла, потом замещала учителя трудового воспитания - и так вот постепенно (гимназия, ж., учитель труда).

Нам известен и противоположный случай, когда инициатором трудоустройства является не кандидат, а школа: когда мать с высшим математическим образованием пришла в школу обсудить качество преподавания математики, получила предложение вести кружок в этой школе и устроилась на работу.

\section{Постепенное продвижение}

Претенденты на должность учителя с недостаточной формальной квалификацией, в частности, не имеющие педагогического образования, или педагоги со средним образованием (например, бывшие воспитателями детского сада) часто сначала ведут группу продленного дня (своего рода испытательный срок, распространенный во многих школах). Кроме того, к этой стратегии может подталкивать и недостаток социальных ресурсов недавних мигрантов. Например, учитель истории и обществознания из поселка Ряймяля Питкярантского района Карелии, после переезда в Санкт-Петербург работала на группе продленного дня воспитателем, а потом уже перевелась «на класс» в начальной школе (СОШ, ж., учитель нач. классов).

Сходным образом работает и прохождение педагогической практики. С точки зрения школы - это осознанная стратегия целенаправленного рекрутинга молодых специалистов, а для будущего учителя - это прежде всего возможность знакомства с коллективом школы и привыкания к нему, часто в сочетании со стратегией постепенного устройства в школу начиная с временной или неполной ставки. Так, одна из респонденток после практики в школе, замещая учителя по биологии, который вскоре уволился, осталась на постоянной ставке (гимназия, ж., учитель биологии).

Ситуации постепенного продвижения к учительской позиции в рамках конкретной школы максимально удалены от модели профессионалов, конкурирующих на общем рынке труда за престижные учительские вакансии. В тех случаях, когда карьерные устремления связаны с конкретной школой, пред- 
ставление о рынке учительских вакансий оказывается нерелевантным, школа здесь выступает как сообщество, связь с которым важна. Этот сценарий характерен как для тех случаев, когда можно говорить о «дефиците» квалификации, не позволяющем занять учительскую позицию сразу, так и для случаев на противоположном конце шкалы престижа, когда информант рассматривает возможность работы только в определенной (известной) школе.

\section{Переход в другую школу}

Высокие значения среднего срока работы в одной школе свидетельствуют о том, что учителя, единожды устроившись в школу, избегают перехода между школами (здесь мы не учитываем тех, кто уходит из учительской профессии совсем или переходит на административные должности). Поэтому среди причин перехода имеет смысл выделить блок внешних обстоятельств, от переезда до расформирования школы, которые мы не будем рассматривать, и блок причин, связанных с собственными устремлениями учителя, в том числе профессиональными.

В качестве одного из наиболее распространенных двигателей, обеспечивающих мобильность учителей, в наших интервью выступают административные перемещения, прежде всего назначения и переводы директоров. Такие перемещения сопровождаются переходом в новую школу тесно связанных с администратором учителей. Новый директор стремится привести своих учителей, а не только наследовать сложившийся коллектив или набирать новых сотрудников:

Просто наш завуч, мой непосредственно завуч по иностранным языкам, она стала директором [этой] школы. Соответственно... у нас были очень такие теплые деловые отношения, мне очень нравилось работать под ее началом (гимназия, ж., учитель иностранного языка и завуч).

Несколько реже причиной перемещения группы учителей становятся конфликты, о которых обычно говорят расплывчато: «каждая школа - отдельное государство, всякое случается в государстве» (СШ английский язык, ж., учитель экономики). В результате конфликта на старом месте работы другой респондент и еще пять преподавателей ушли из гимназии вместе, и директор - знакомая одной из коллег, «взяла к себе, поэтому не было выбора, куда уходить, мы большим составом ушли в эту школу» (СШ английский язык, ж., учитель музыки).

Другой класс обстоятельств смены места работы можно условно обозначить как «освобождение» от вынужденного (например, по распределению РОНО) трудоустройства и переход к более желательному месту работы при первой возможности. После переезда в Санкт-Петербург из Нальчика учитель (СОШ, ж., русский язык и литература) устроилась в вечернюю школу для взрослых - место работы, не удовлетворявшее ее 
экономическим потребностям и профессиональным претензиям. Но директор рассказал об открывшейся вакансии в соседней средней школе. Таким образом, даже попав в недостаточно престижную, с точки зрения респондента, школу, она обрастает знакомствами в школьной среде, позволяющими найти другое место работы.

Двигателем, помогающим учителю перейти на работу в более престижную школу, может послужить и собственная административная или профессиональная карьера в школе. Учительница, ставшая директором непрестижной школы на окраине города, вынужденно покинула эту должность по семейным обстоятельствам, и вернулась на должность учителя, но, благодаря контактам с директорами районных школ, уже в одном из сильных физико-математических лицеев (лицей, ж., учитель русского и литературы). Лишь один учитель в качестве причины перехода упомянул учеников: «Я работала в $N$ школе, а эту школу только построили, и мой класс перевели сюда, ну и я с ними. Я была классным руководителем, ну как я их брошу» (СОШ, ж., математика). Примечательно, что и при обсуждении гипотетической ситуации смены школы учителя никогда не называли в качестве мотива стремление перейти в школу с более мотивированными к обучению учащимися.

Если исключить из рассмотрения внешние обстоятельства, оказывается, что учителя редко мотивируют переход в другую школу собственными профессиональными и карьерными устремлениями. Обобщая описанные случаи смены школ, можно выделить два типа мотивов к перемене места работы: (1) вызванные собственными соображениями и обстоятельствами учителя (семейными, карьерными, прагматическими) и (2) спровоцированные перемещениями коллег. Отношения в школьном педагогическом коллективе воспринимаются как чрезвычайно важный фактор, вокруг которого часто строится нарратив (ср., Рощина, Филиппова 2012). Это демонстрирует, что для уже работающего в школе учителя центральным мотивом выбора места работы становятся социальные связи в среде учителей, прежде всего в коллективе той школы, в которой работает. Следствиями этого обстоятельства оказываются как относительно высокая стабильность школьных коллективов, так и характерный паттерн групповых перемещений учителей.

\section{Дискуссия}

Анализ интервью с учителями о выборе школы и смене места работы выявил несколько разных моделей трудоустройства. Мы обнаружили, что критерии выбора места работы, которые озвучивают учителя в нарративах о трудоустройстве в школу, связаны с уровнем квалификации учителя. На основании проанализированных интервью можно предположить, что следование этим критериям приводит учителей в разные по уровням престижа школы. 
Можно выстроить градиент от самых престижных школ, учителя которых озвучивают максимум профессиональных критериев в ситуации выбора места работы, до самых непрестижных школ, где у соискателей доминирует представление о том, что «все школы одинаковы», и на первый план при выборе места работы выходит географический принцип. Таким образом, в сегменте престижных школ, наиболее приближенном к модели, где профессионалы конкурируют за позиции более и менее престижных работодателей, доступ к квалифицированным учителям будет в большой степени определяться условиями труда, которые могут предложить школы. Напротив, в сегменте непрестижных школ доступ к квалифицированным учителям будет во многом зависеть от географического положения - школы будут более зависимы от того, какие учителя живут по соседству.

Стратегии первого типа трудоустройства не соотносятся напрямую с квалификацией учителя. Обозначенная нами «аутсайдерская» модель предполагает процедуры трудоустройства, характерные для рынка квалифицированного труда (публикация вакансий, поиск информации о работодателе, серия интервью). Критерии, которыми руководствуются следующие этой модели трудоустройства учителя при выборе школ, тесно связаны с их собственной квалификацией и уровнем престижа школ, на которые они ориентированы. Однако в рамках этой же стратегии выделяется «обзвон» или обход школ по соседству, характерный для учителей непрестижных школ.

Используя условный ярлык «инсайдерской» модели, мы подчеркиваем, что отправной точкой при трудоустройстве здесь оказывается не наличие вакансии, а социальные контакты с коллективом школы и стремление присоединиться к нему. Описанные нами стратегии трудоустройства, находящиеся в рамках этой модели, могут служить механизмом воспроизводства социального профиля школьных коллективов. Здесь следует назвать прежде всего инбридинг (трудоустройство выпускников школы на работу учителями в ней), который характерен для всех типов школ, вне зависимости от уровня их престижа.

Значимым фактором, приводящим к неравному доступу школ к квалифицированным учителям, является в рамках этой модели не географическая, а социальная сегментация рынка труда (круги знакомств). В условиях углубляющейся социальной дифференциации учащихся в зависимости от успешности школы, инбридинг при трудоустройстве может оказаться механизмом, поддерживающим социальную дифференциацию и воспроизводящим школьные учительские коллективы. Подобный механизм срабатывает и в случае трудоустройства учителей в ту школу, где учатся их дети,- в этой ситуации выбор места работы совмещается с находящимся под сильным влиянием шкалы престижа выбором школы для обучения детей.

Заметное место среди причин перемещения учителей между школами занимает переход учителей вместе с администратором, назначенным в другую школу. Этот тип перемещений приобретает массовость за счет общепринятой 
в российских школах практики назначать завучей школ на работу директорами в другие школы. Учителя ориентируются на коллег и отношения с ними, переходы на другое место работы часто осуществляются коллективно.

\section{Заключение}

Обнаруженный спектр стратегий трудоустройства показывает, что в мегаполисе пространство выбора места работы для разных учителей структурировано очень разнообразно. В рамках этой структуры сосуществуют шкалы престижа, географической близости и личных социальных связей в школьном сообществе. Предпочтение тех или иных стратегий трудоустройства в школах разного уровня престижа может служить одним из факторов, влияющих на распределение учителей по школам. Меры образовательной политики, направленные на привлечение и удержание квалифицированных учителей в школах, должны учитывать тот факт, что выбор школ при поиске места работы - это фактор, от которого в большой мере зависит, какие школы получат возможность найма квалифицированных учителей.

\section{Выражения благодарности}

Работа выполнена при поддержке гранта РГНФ 14-03-00582 «Статусные группы, карьерные траектории и идентичности школьных учителей» и дополнительного финансирования Научным фондом НИУ ВШЭ. Мы благодарны нашим коллегам, участвовавшим в проекте, и анонимным рецензентам журнала за ценные замечания.

\section{Список источников}

Вахштайн В.С., Константиновский Д. Л., Куракин Д. Ю. (2009) Между двумя волнами мониторинга (2007-2008). Тенденции развития образования: 20 лет реформ, что дальше? М.: Университетская книга.

Дербишир Н.С., Пинская М.А. (2016) Управленческие стратегии директоров эффективных школ. Вопросы образования, (3): 110-129.

Иванюшина В.А., Александров Д. А. (2016) Существует ли дифференциация учителей в российских школах? Социологические исследования, (9): 59-65.

Константиновский Д. Л. (2008) Неравенство и образование: Опыт соииологических исследований жизненного старта российской молодежи (1960-е годы - начало 2000-x), М.: ЦСП.

Косарецкий С.Г., Пинская М.А., Мерцалова Т. А., Деркачев П. В., Савельева М.Б. (2015) Политика общеобразовательных учреждений по результатам опроса их руководителей. Информационный бюллетень, М.: НИУ ВШЭ.

Ленская Е. (ред.) (2015) Российские педагоги в зеркале международного сравнительного исследования педагогического корпуса (TALIS 2013), М.: НИУ ВШЭ. 
Маслинский К.А., Иванюшина В.А. (2016) Остаться учителем? Факторы, влияющие на отношение к уходу из учительской профессии. Вопросы образования, (4): 8-30.

Пинская М.А., Фрумин И. Д., Косарецкий С. Г. (2012) Школы, работающие в сложных социальных контекстах. И. Фрумин (ред.) Выравнивание шансов детей на качественное образование, М.: Издательский дом ВШЭ: 9-36.

Рощина Я.Н., Филиппова Т.М. (2012) Учителя и воспитатели на рынке труда: частные и государственные школь и ДОУ в 2006-2011 г2. Информационный бюллетень, М.: НИУ ВШЭ.

Akiba M., LeTendre G.K., Scribner J.P. (2007) Teacher Quality, Opportunity Gap, and National Achievement in 46 Countries. Educational Researcher, 36 (7):369-387.

Boyd D.J., Grossman P., Lankford H., Loeb S., Michelli N. M., Wyckoff J. (2006) Complex by Design Investigating Pathways into Teaching in New York City Schools. Journal of Teacher Education, 57 (2): 155-166.

Boyd D., Lankford H., Loeb S., Wyckoff J. (2005). The Draw of Home: How Teachers' Preferences for Proximity Disadvantage Urban Schools. Journal of Policy Analysis and Management, 24 (1): 113-132.

Hanushek E., Kain J., Rivkin S. (2004) Why Public Schools Lose Teachers. Journal of Human Resources, 39 (2): 326-354.

Ingersoll R. M. (2001) Teacher Turnover and Teacher Shortages: An Organizational Analysis. American Educational Research Journal, 38 (3): 499-534.

Jacob B.A. (2007) The Challenges of Staffing Urban Schools with Effective Teachers. The Future of Children, 17 (1): 129-153.

Lankford H., Loeb S. and Wyckoff J. (2002) Teacher Sorting and the Plight of Urban Schools: A Descriptive Analysis. Educational Evaluation and Policy Analysis, 24 (1):37-62.

Lindqvist P., Nordänger U.K. (2016) Already elsewhere - A study of (skilled) teachers' choice to leave teaching. Teaching and Teacher Education: An International Journal of Research and Studies, 54: 88-97.

Maier A., Youngs P. (2009) Teacher Preparation Programs and Teacher Labor Markets: How Social Capital May Help Explain Teachers' Career Choices. Journal of Teacher Education, 60 (4):393-407.

Schaefer L., Downey C. A., Clandinin D. J. (2014) Getting Beyond Elevator Stories. Advances in Research on Teaching, (23): 1-11. 
Vlada Baranova, Kirill Maslinsky

\title{
THE EMPLOYMENT STRATEGIES OF TEACHERS IN LARGE CITIES AND THE DIFFERENTIATION OF SCHOOLS
}

\begin{abstract}
In this article we discuss the strategies used by teachers in job-seeking as one factor behind uneven access levels of higher and lower-achieving schools when hiring qualified teachers. Our central hypothesis is that these job-seeking strategies vary depending on qualification level and professional achievement. Empirical data for the study was collected in Saint Petersburg in schools with varying levels of achievement and prestige. We conducted interviews with teachers $(\mathrm{N}=49)$ on their professional biography. For analysis we used two points in an individual teacher's career: the choice of the first school in the teacher's career path and decision-making when switching schools. The results of the study show that several models of job seeking coexist on the teaching job market. We distinguish two narrative perspectives that a teacher may take when telling of her employment. Within an outsider's perspective schools are regarded as organizations that may be potential employers. One model is similar to the market of other qualified jobs, where professionals compete for more or less prestigious positions. The other model, which is more similar to the unqualified job market, is based on the tacit assumption that all schools are equal and places more importance on the workplace's geographical proximity. Within an insider's perspective teachers regard their potential employing schools primarily as professional communities they may wish to join. There are several types of social bonds that may be used by a person seeking employment as a school teacher. These includes seeking a job in a school one has graduated from ('inbreeding') and seeking a job in a school where one's children study. Both strategies may lead to the social background of school's teachers being reproduced. We argue that the job seeking strategies of teachers based on social ties can be understood as a mechanism that supports the movement of qualified teachers to disadvantaged schools.
\end{abstract}

Keywords: school, teachers, professional group, labour market, educational inequality

DOI: 10.17323/727-0634-2017-15-2-281-296

\section{References}

Akiba M., LeTendre G.K., Scribner J.P. (2007) Teacher Quality, Opportunity Gap, and National Achievement in 46 Countries. Educational Researcher, 36 (7):369-387.

Vlada Baranova - department of Sociology, Associate Proffessor, National research university Higher school of economics, Saint Petersburg, Russian Federation. Email: vbaranova@hse.ru

Kirill Maslinsky - research fellow, Laboratory for sociology of education and science, National research university Higher school of economics, Saint Petersburg, Russian Federation. Email: kmaslinsky@hse.ru 
Boyd D.J., Grossman P., Lankford H., Loeb S., Michelli N. M., Wyckoff J. (2006) Complex by Design Investigating Pathways into Teaching in New York City Schools. Journal of Teacher Education, 57 (2): 155-166.

Boyd D., Lankford H., Loeb S., Wyckoff J. (2005). The Draw of Home: How Teachers' Preferences for Proximity Disadvantage Urban Schools. Journal of Policy Analysis and Management, 24 (1): 113-132.

Hanushek E., Kain J., Rivkin S. (2004) Why Public Schools Lose Teachers. Journal of Human Resources, 39 (2): 326-354.

Ingersoll R. M. (2001) Teacher Turnover and Teacher Shortages: An Organizational Analysis. American Educational Research Journal, 38 (3): 499-534.

Ivanjushina V. A., Aleksandrov D. A. (2016) Sushhestvuet li differenciacija uchitelej v rossijskih shkolah? [Does Differentiation of Teachers Exist in Russian Schools?]. Sociologicheskie issledovanija, 9:59-65.

Jacob B. A. (2007) The Challenges of Staffing Urban Schools with Effective Teachers. The Future of Children, 17 (1): 129-153.

Konstantinovskiy D. L. (2008) Neravenstvo i obrazovanie: Opyt sotsiologicheskikh issledovaniy zhiznennogo starta rossiyskoy molodezhi (1960-e gody - nachalo 2000-kh) [Inequality and Education: The Case of Sociological Study of Life Start of Russian Youth (1960s - Early 2000s)], Moscow: TsSP.

Kosareckij S.G, Pinskaja M.A., Mercalova T. A., Derkachev P. V., Savel'eva M.B. (2015) Politika obshheobrazovatel'nyh uchrezhdenij po rezul'tatam oprosa ih rukovoditelej. Informacionnyj bjulleten' [Politics of General Educational Institutions Represented in a Survey of School Leaders. Informational Bulletin], Moscow: NIU VShJe.

Lankford H., Loeb S. and Wyckoff J. (2002) Teacher Sorting and the Plight of Urban Schools: A Descriptive Analysis. Educational Evaluation and Policy Analysis, 24 (1):37-62.

Lenskaya E. (ed.) (2015) Rossijskie pedagogi v zerkale mezhdunarodnogo sravnitel'nogo issledovanija pedagogicheskogo korpusa (TALIS 2013) [Russian Teachers in the Mirror of an International Comparative Study of the Teaching Corpus (TALIS 2013)], Moscow: Izdatel'skiy dom VShE.

Lindqvist P., Nordänger U.K. (2016) Already Elsewhere - A Study of (skilled) Teachers' Choice to Leave Teaching. Teaching and Teacher Education: An International Journal of Research and Studies, (54): 88-97.

Maier A., Youngs P. (2009) Teacher Preparation Programs and Teacher Labor Markets: How Social Capital May Help Explain Teachers' Career Choices. Journal of Teacher Education, 60 (4):393-407.

Maslinskij K. A., Ivanjushina V.A. (2016) Ostat'sja uchitelem? Faktory, vlijajushhie na otnoshenie k uhodu iz uchitel'skoj professii [To Remain a Teacher? Factors Influencing Attitudes Leaving the Teaching Profession]. Voprosy obrazovanija, (4): 8-30.

Pinskaya M. A., Frumin I. D., Kosaretskiy S. G. (2012) Shkoly, rabotayushchie v slozhnykh sotsial'nykh kontekstakh [Schools that Work in Complex Social Contexts]. I. Froumin (ed.). Vyravnivanie shansov detey na kachestvennoe obrazovanie [Equalizing Children's Opportunities for Quality Education], Moscow: Izdatel'skiy dom VShE: 9-36.

Roshhina Ja.N., Filippova T. M. (2012) Uchitelja i vospitateli na rynke truda: chastnye i gosudarstvennye shkoly i DOU v 2006-2011 gg. Informacionnyj bjulleten' [Teachers and Tutors in the Labor Market: Private and State Schools and DOU in 2006-2011. Informational bulletin], Moscow: NIU VShJe.

Schaefer L., Downey C. A., Clandinin D. J. (2014) Getting Beyond Elevator Stories. Advances in Research on Teaching, (23): 1-11.

Vakhshtayn V. S., Konstantinovskiy D. L., Kurakin D. Yu. (2009) Mezhdu dvumya volnami monitoringa (2007-2008). Tendentsii razvitiya obrazovaniya: 20 let reform, chto dal'she? [Between Two Waves of Monitoring (2007-2008). Tendencies of the Development of Education: 20 Years of Reforms, What Next?)], Moscow: Universitetskaya kniga. 